\title{
Radar rainfall estimation for the post-event analysis of a Slovenian flash-flood case: application of the Mountain Reference Technique at C-band frequency
}

\author{
L. Bouilloud ${ }^{1}$, G. Delrieu ${ }^{1}$, B. Boudevillain ${ }^{1}$, M. Borga ${ }^{2}$, and F. Zanon ${ }^{2}$ \\ ${ }^{1}$ Laboratoire d'étude des Transferts en Hydrologie et Environnement, Grenoble, France \\ ${ }^{2}$ Dept. of Land and Agroforest Environment, University of Padova, Legnaro, Italy
}

Received: 16 December 2008 - Published in Hydrol. Earth Syst. Sci. Discuss.: 30 January 2009

Revised: 29 June 2009 - Accepted: 29 June 2009 - Published: 29 July 2009

\begin{abstract}
This article is dedicated to radar rainfall estimation for the post-event analysis of a flash flood that occurred on 18 September 2007 in Slovenia. The utility of the Mountain Reference Technique is demonstrated to quantify rain attenuation effects that affect $\mathrm{C}$-band radar measurements in heavy rain. Maximum path-integrated attenuation between 15 and $20 \mathrm{~dB}$ were estimated thanks to mountain returns for path-averaged rain rates between 10 and $15 \mathrm{~mm} \mathrm{~h}^{-1}$ over a $120-\mathrm{km}$ path. Assuming the reflectivity-attenuation relationship to be known, the proposed technique allows for estimating an effective radar calibration correction factor to be accounted for in the parameterization of the attenuation correction. Screening effects are quantified using a geometrical calculation based on a digitized terrain model of the region. The vertical structure of the reflectivity is modeled with a normalized apparent vertical profile of reflectivity. Implementation of the radar data processing indicates that: (1) the combined correction for radar calibration and attenuation effects allows for obtaining satisfactory radar rain estimates (Nash criterion of 0.8 at the event time scale); (2) due to the attenuation equation instability, it is however compulsory to limit the maximum path-integrated attenuation to be corrected to about $10 \mathrm{~dB}$; (3) the results also prove to be sensitive on the parameterization of reflectivity-attenuation-rainrate relationships.
\end{abstract}

\section{Introduction}

The HYDRATE project funded by the European Community (http://www.hydrate.tesaf.unipd.it/) aims at improving the scientific basis of flash flood forecasting by extending the understanding of past flash flood events, advancing and

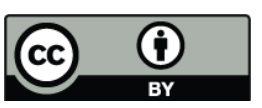

Correspondence to: L. Bouilloud (ludovic.bouilloud@hmg.inpg.fr) harmonizing a European-wide innovative flash flood observation strategy and developing a coherent set of technologies and tools for effective early warning systems. Weather radars offer unprecedented means for observing extreme rain events with space and time resolution relevant with respect to the hydrological dynamics of the affected watersheds (e.g., Smith et al. 1996; Ogden et al., 2000; Delrieu et al., 2005). However, the complexity of the radar technology, the variety of uncertainty sources and the variability of precipitation at all scales still make the radar quantitative precipitation estimation (QPE) a very challenging task. This is especially true in mountainous regions (e.g., Joss and Waldvogel, 1990; Andrieu et al., 1997; Germann et al., 2006; Delrieu et al., 2009) due to the impact of the orography on the propagation of the electromagnetic waves (clutter due to the relief and anthropic targets; screening; anomalous propagation). The radar QPE quality depends much on the relative locations of the radar and the rain event, the intervening relief, the radar parameters, the operating protocol and the data processing (Pellarin et al., 2002).

With respect to the extreme event-driven observation strategy promoted in the HYDRATE project, very pragmatic approaches need to be developed to take the best benefit of existing weather radar and raingauge datasets for post-event rainfall estimation in mountainous regions. The present paper offers an example with the heavy rains and flash floods that occurred on 18 September 2007 in Slovenia (Fig. 1) causing seven human casualties and damage costs evaluated to 285 million Euros. More than 40 municipalities, i.e. about one third of the country, were affected by this event. The town of Železniki, located at about $50 \mathrm{~km}$ north-west of Ljubljana, was particularly affected by the disaster (3 casualties, 100 million Euros of damages). The flood swept away cars, buses and severely damaged homes, a hospital and a water treatment plant. The Železniki town is located on the Selška Sora river. The corresponding watershed has an area

Published by Copernicus Publications on behalf of the European Geosciences Union. 

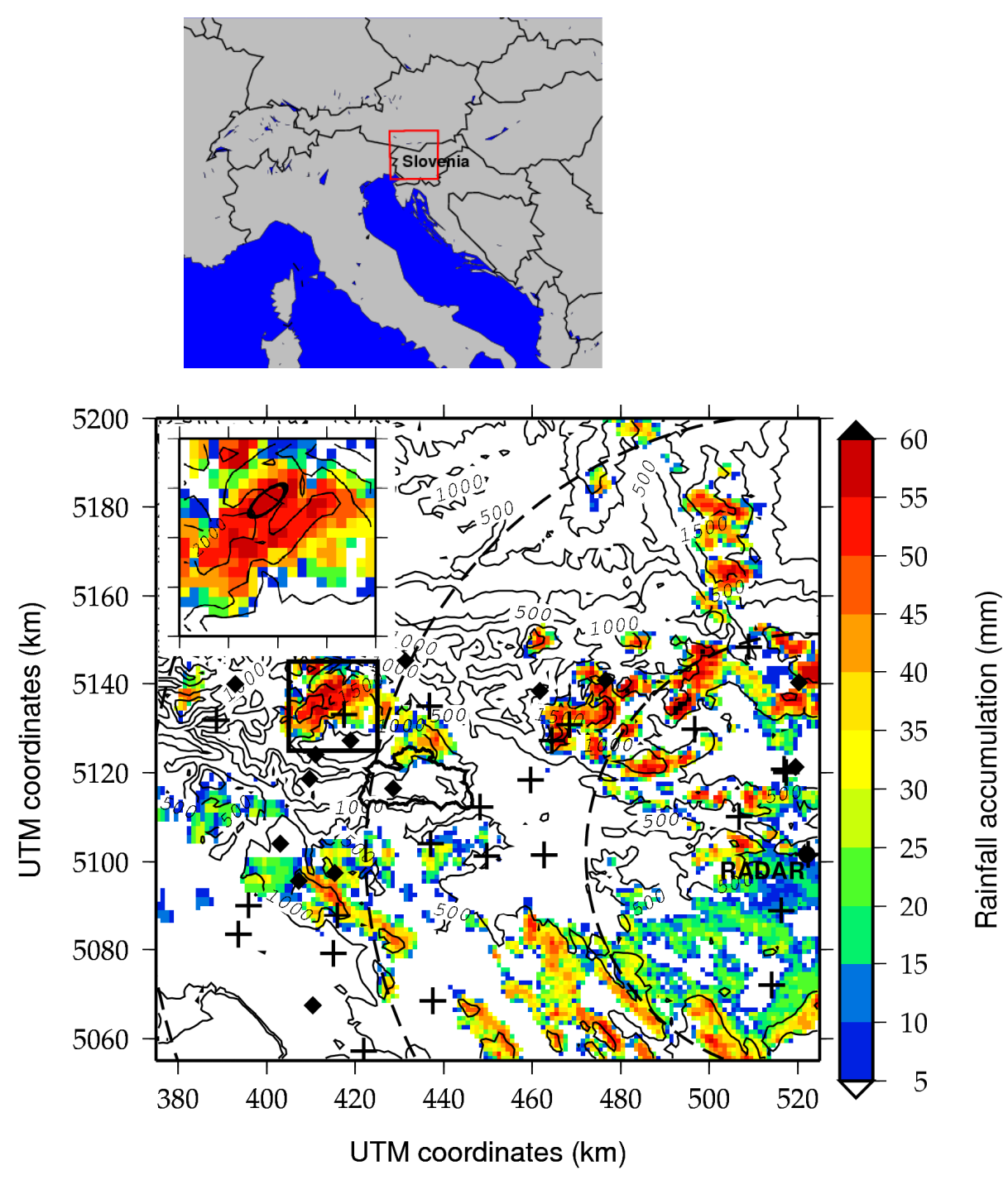

Fig. 1. Map of the study area in Slovenia. The terrain contours are displayed with $100-\mathrm{m}$ isolines, the location of daily raingauges with plus signs, hourly raingauges with black diamonds, the Lisca C-band radar with 50-km range markers. The Sora watershed at Železniki is delineated in the center of the image with a black contour. The dry-weather clutter (in dBZ) is displayed for the lowest elevation angle $\left(0.5^{\circ}\right)$. The reference mountain target used for the MRT application is delineated by the black square, and a zoom is displayed within the inset in the left upper corner. Within the inset, the black ellipse represents the radar bins used for computation.

of approximately $200 \mathrm{~km}^{2}$. The single raingauge within the watershed indicated a rain event mostly concentrated in $5 \mathrm{~h}$ with a total amount of $220 \mathrm{~mm}$. The maximum discharge was estimated to $350 \mathrm{~m}^{3} \mathrm{~s}^{-1}$ from an operational station located downstream of the city. This corresponds to a maximum specific discharge of about $1.75 \mathrm{~m}^{3} \mathrm{~s}^{-1} \mathrm{~km}^{-2}$. Such characteristics motivated a post-event survey, conducted by $21 \mathrm{HY}$ DRATE scientists from different institutions and countries (UK, Italy, France, Greece, Romania, Spain and Slovakia) with the support of the Environmental Agency of the Republic of Slovenia (ARSO; http://www.arso.gov.si/en/). In addition to operational hydrological data, in situ information was gathered from cross-section surveys to estimate maximum discharges for ungauged watersheds and from interviews of witnesses to document the chronology of the floods, following the methodology described by Gaume (2006).

We concentrate in this article on the rainfall estimation problem. The layout of the available rainfall observation system managed by ARSO is displayed in Fig. 1. It includes a network of 47 raingauges (among them, 14 devices provide time series at the hourly time step while the remaining ones are daily raingauges) and a modern volume-scanning Doppler C-band radar located in Lisca at about $80-100 \mathrm{~km}$ from the affected watershed. As such, this example is quite representative of the post-event analysis context with radar data coming from a rather remote system, a relatively dense 
network of daily raingauges and few hourly raingauge time series. The overall strategy is therefore to use the raingauge data to control/assess the radar data processing prior to using the radar QPE space-time series as input in rainfall-runoff models. A first aim of the present contribution is to test the utility of the Mountain Reference Technique (MRT) for quantifying and correcting rain attenuation effects that are likely to severely affect C-band radar measurements in heavy rain (Delrieu et al., 2000). The MRT refers to the Surface Reference Technique proposed by Meneghini et al. (1983) for rainfall measurement at attenuating wavelengths in spaceborne radar configurations. The concept is based on the estimation of path-integrated attenuation (PIA) from the difference between the Earth surface radar return in the presence and in the absence of rain. Such measurements can be used in various ways to estimate the average rain rate over the propagation path and/or to constrain rain rate profiling algorithms (Marzoug and Amayenc, 1994). Feasibility of applying this technique to ground-based radars with mountain returns was already demonstrated for the $\mathrm{X}$-band, a frequency band severely prone to rain attenuation effects (Delrieu et al., 1997; Serrar et al., 2000).

Section 2 shows evidence of very significant rain attenuation effects at C-band for the Slovenian case. The way such PIAs can be used to correct attenuation over the entire radar detection domain is the subject of Sect. 3. In Sect. 4, the attenuation correction is placed in the broader context of the radar quantitative precipitation estimation, using the TRADHy radar processing system developed at LTHE (Delrieu et al., 2009; TRADHy stands for Traitements Régionalisés et Adaptatifs de données radar pour l'Hydrologie / regionalized and adaptive radar data processing for hydrological applications). Section 5 provides a series of sensitivity tests and assessments of the radar QPEs with respect to raingauge data. Finally, the main results of this work are summarized in Sect. 6 .

\section{Evidence of rain attenuation at C-band using mountain returns}

Table 1 lists the parameters of the Lisca C-band radar. Figure 1 displays the dry-weather ground clutter for the lowest radar elevation angle $\left(0.5^{\circ}\right)$ averaged over a 7 -h period preceding the 18 September 2007 rain event. It should be noted that raw reflectivity data is (fortunately) stored by ARSO in polar format, prior to and after implementation of the ground clutter filtering technique. The ground-cluttered reflectivity data is quite naturally not used in any manner in operational practice although we are going to show it contains valuable information for radar QPE. As the reference target, we selected a strong ground clutter pattern that can be seen at about $20 \mathrm{~km}$ in the North-west direction of the Železniki watershed (delineated by the inset in Fig. 1). Figure 2 shows the time evolution of the average value of the reference target together

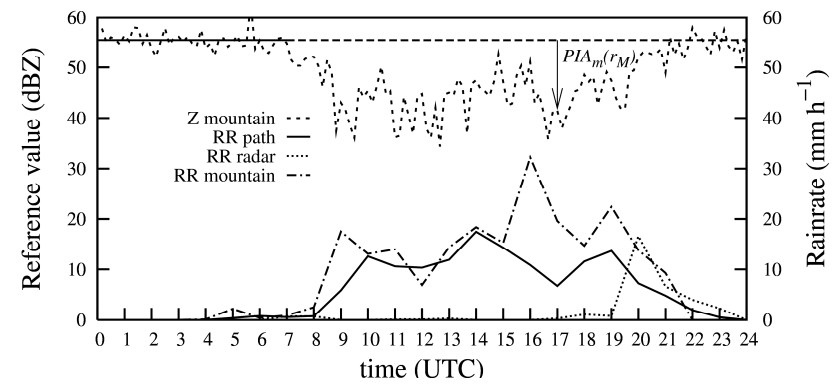

Fig. 2. Time series of the mountain reference target value (dashed line on top), the average rainrate along the path (bottom part of the graph, continuous line), the rainrate in the vicinity of the mountain (dash-dotted line) and the rainrate close to the radar site (dotted line).

with various rainfall indicators derived from the raingauge network measurements: these include (1) the average rainrate along the radar - reference target path obtained with the available hourly raingauges through the Thiessen technique; (2) the rainrate time series of the closest raingauge to the reference target and (3) the rainrate time series of the closest raingauge to the radar site. The intensity of the reference target decreases when rain occurs between the radar and the target and it recovers its initial value at the end of the rain event. The PIA reaches maximum values between 15 and $20 \mathrm{~dB}$ for path-averaged rain rates between 10 and $15 \mathrm{~mm} \mathrm{~h}^{-1}$ over a $120-\mathrm{km}$ path. Such high PIA values at C-band were already observed (Geotis, 1975) or simulated (Delrieu et al., 2000). For the hydrologists not familiar with $\mathrm{dB}$ units, these PIA values correspond to multiplicative factors of 31.6 and 100 , respectively, on the reflectivity and to multiplicative factors of 10 and 21.5, respectively, on the rain rate if the exponent of the $Z-R$ relationship is equal to 1.5 . Compared to the hourly rainrate time series, it is noteworthy that the reference target time series presents a rather high degree of fluctuation from one step to the next. This is related to the fact that the reflectivity measurements are made instantaneously once every $10 \mathrm{~min}$. The rain event was also characterized by fast-moving convective cells, which may also contribute to increase the noise in the reference target time series. Like attenuation measurement with microwave links (e.g., Leijnse et al., 2007), the PIA estimation in the present configuration may also be affected by on-site effects. Since the Lisca C-band radar is equipped with a radome, special care needs to be taken when and after rainfall occurs at the radar site: the presence of a water film on the radome is known to produce attenuation effects of several dB (Collier, 1989). Fortunately, rainfall occurred at the radar site only at the end of the rain event, well after the intense rainy period in the Železniki area. Rainfall falling over the reference target may also affect the PIA estimation (negative bias) as shown by Delrieu et al. (1999b) who proposed a simple approach to cope with this effect. 


\section{Attenuation correction}

We recall hereafter the principle of the MRT and the way the attenuation correction parameters are estimated. Details may be found in Marzoug and Amayenc (1994), Delrieu et al. (1997) and Serrar et al. (2000).

\subsection{Principle of the Mountain Reference Technique}

Let us define the measured rain reflectivity factor profile $Z_{m}(r)\left[\mathrm{mm}^{6} \mathrm{~m}^{-3}\right]$ as:

$Z_{m}(r)=Z(r) \delta_{c} A(r)$

where $r$ is the range, $Z\left[\mathrm{~mm}^{6} \mathrm{~m}^{-3}\right]$ is the true reflectivity factor, $\delta_{c}[-]$ is a radar calibration correction factor, $A(r)[-]$ is the rain attenuation factor along the path from the radar to range $r$. In Eq. (1), only two sources of error are considered: a possible radar miscalibration supposed to be constant in time (i.e. we assume that the transmitter-receiver unit is stable within the measurement period) and the effect of attenuation by rainfall between the radar and range $r$.

The PIA factor is given by:

$A(r)=\exp \left(-\frac{2 \ln (10)}{10} \int_{0}^{r} k(s) d s\right)$

where $k$ is the attenuation coefficient $\left[\mathrm{in} \mathrm{dB} \mathrm{km}^{-1}\right]$ that depends on the working wavelength and on the rain drop size distribution (DSD) and temperature. We define the PIA in $\mathrm{dB}$ units as PIA $(r)=-10 \log A(r)$.

Assuming that the relation between the reflectivity factor and the attenuation coefficient can be satisfactorily represented by a power law model, with $Z=\alpha k^{\beta}$, it can be shown (Marzoug and Amayenc, 1994; Delrieu, et al. 1997) that:

$A(r)=\left[A\left(r_{0}\right)^{1 / \beta}-\frac{S\left(r_{0}, r\right)}{\delta_{c}^{1 / \beta}}\right]^{\beta}$

with

$S\left(r_{0}, r\right)=\frac{2 \ln (10)}{10 \beta} \int_{r_{0}}^{r}\left[\frac{Z_{m}(s)}{\alpha}\right]^{1 / \beta} d s$

In Eq. (3), $r_{0}$ represents the so-called "blind range", that is the range where the reflectivity sampling is started and/or where the reflectivities can be considered as free of ground clutter due to side lobes. The term $A\left(r_{0}\right)$ is related to both radome attenuation and rain attenuation between 0 and $r_{0}$. Equations (3) and (4) indicate that the PIA factor at any range $r$ can be obtained as a function of the measured reflectivity profile $Z_{m}(r)$, the coefficients $\alpha$ and $\beta$ of the $Z-k$ relationship, the blind range attenuation factor $A\left(r_{0}\right)$ and the calibration error $\delta_{c}$.
Table 1. Lisca C-band radar parameters.

\begin{tabular}{lc}
\hline Parameter & Value $(\mathrm{s})$ \\
\hline Geographical coordinates & Lat $=46.068^{\circ}$, Lon $=15.290^{\circ}$, Alt $=950 \mathrm{~m}$ m.s.l. \\
Measured parameters & Reflectivity, radial velocity, spectrum width \\
Wavelength $(\mathrm{cm})$ & 5.34 \\
Peak power $(\mathrm{kW})$ & 300 \\
PRF $(\mathrm{Hz})$ & 600,1200 \\
Pulse length $(\mu \mathrm{s})$ & 0.8 \\
Minimum detectable signal $(\mathrm{dBm})$ & -110 \\
Antenna diameter $(\mathrm{m})$ & 4.2 \\
3-dB beamwidth $\left({ }^{\circ}\right)$ & 0.9 \\
Power gain $(\mathrm{dB})$ & 43.8 \\
Operating protocol & 12 elevations; revisit time of $10 \mathrm{~min}$ \\
& $11.6,2.4,3.4,4.7,6.3,8.6^{\circ}(3 \mathrm{rpm} ; 600 \mathrm{~Hz})$ \\
Polar data reflectivity quantization & $-30.9,28.4^{\circ}(3 \mathrm{rpm} ; 1200 \mathrm{~Hz}$ to $90 \mathrm{dBZ}$ with $0.5 \mathrm{dBZ}$ increment \\
Polar data resolution & $1000 \mathrm{~m}$ (radial); $1^{\circ}$ (angular); from 1 to $250 \mathrm{~km}$ \\
\hline
\end{tabular}

If we consider a range $r_{M}$ where a reference target (a mountain here) is available, the PIA calculated from the measured reflectivity profile ( $\operatorname{PIA}_{c}\left(r_{M}\right)$ hereafter) can be written as:

$\operatorname{PIA}_{c}\left(r_{M}\right)=-10 \log \left(\left[A\left(r_{0}\right)^{1 / \beta}-\frac{S\left(r_{0}, r_{M}\right)}{\delta_{c}^{1 / \beta}}\right]^{\beta}\right)$

The simplest estimator for the PIA from mountain returns can be expressed through the following equation:

$\operatorname{PIA}_{m}\left(r_{M}\right)=-10 \log \left[\frac{Z_{\mathrm{dry}}^{\mathrm{ref}}\left(r_{M}\right)}{Z_{\text {rain }}^{\mathrm{ref}}\left(r_{M}\right)}\right]$

where $Z_{\mathrm{dry}}^{\mathrm{ref}}\left(r_{M}\right)$ and $Z_{\mathrm{rain}}^{\mathrm{ref}}\left(r_{M}\right)$ are the mean reflectivity of the reference target during dry and rainy time steps, respectively. The practical procedure for estimating $\operatorname{PIA}_{m}\left(r_{M}\right)$ is described in Delrieu et al. (1999b): this includes the definition of a baseline and consideration of rainfall falling over the reference target. The so-called PIA constraint equation stipulates that the PIA calculated at range $r_{M}$ from the reflectivity profile should be equal to the PIA derived from the mountain return at any time $t$ during the rain event:

$\mathrm{PIA}_{c}\left(r_{M}, t\right) \equiv \operatorname{PIA}_{m}\left(r_{M}, t\right)$

\subsection{Parameter estimation}

Equations (4), (5), and (6) show that the PIA constraint Eq. (7) depends on three parameters: the coefficients $\alpha$ and $\beta$ of the $Z-k$ relationship and the radar calibration factor $\delta_{C}$. Besides the mean reflectivity of the reference target and the measured reflectivity profiles between the radar and the mountain, specification of the blind-range attenuation $A\left(r_{0}\right)$ is required. As already mentioned, rainfall occurred at the radar site only at the end of the rain event (Fig. 2). The PIA values of the corresponding time steps were then simply discarded from the optimization procedure. The blind-range attenuation factor $A\left(r_{0}\right)$ was supposed to be equal to 1 in the calculation of $\operatorname{PIA}_{c}\left(r_{M}\right)$ for the other time steps. 
Table 2. Coefficients of the $Z=\alpha k^{\beta}$ and $Z=a R^{b}$ relationships for the C-band frequency and a raindrop temperature of $10^{\circ} \mathrm{C}$ using the Mie scattering model and DSD models proposed in the literature (see the review in Delrieu et al., 2000). The other columns give the optimal radar calibration factor $\delta_{C}$, the Nash criterion (Nash) between the measured and calculated PIAs and the number of divergences $\left(N_{\text {div }}\right)$ of the attenuation equation for the optimal $\delta_{C}$ value; $N$ is the total number of PIA pairs considered for the optimization.

\begin{tabular}{|c|c|c|c|c|c|c|c|c|}
\hline DSD model & $\begin{array}{c}Z-k \text { relationship } \\
Z\left[\mathrm{~mm}^{6} \mathrm{~m}^{-3}\right] \\
k\left[\mathrm{~dB} \mathrm{~km}^{-1}\right] \\
\alpha\end{array}$ & $\beta$ & $\begin{array}{c}Z-R \text { relationship } \\
Z\left[\mathrm{~mm}^{6} \mathrm{~m}^{-3}\right] ; \\
R\left[\mathrm{~mm} \mathrm{~h}^{-1}\right] \\
a\end{array}$ & $b$ & $\begin{array}{l}\delta_{C} \\
{[-]}\end{array}$ & $\begin{array}{c}\text { Nash } \\
{[-]}\end{array}$ & $\begin{array}{c}N_{\mathrm{div}} \\
{[-]}\end{array}$ & $\begin{array}{c}N \\
{[-]}\end{array}$ \\
\hline $\begin{array}{l}\text { Widespread } \\
\text { rainfall }\end{array}$ & $5.39 \times 10^{5}$ & 1.16 & 242 & 1.43 & 0.59 & 0.37 & 7 & 51 \\
\hline $\begin{array}{l}\text { Cévennes } \\
\text { rainfall }\end{array}$ & $4.98 \times 10^{5}$ & 1.09 & 362 & 1.40 & 0.56 & 0.33 & 10 & 51 \\
\hline $\begin{array}{l}\text { Thunderstorm } \\
\text { rainfall }\end{array}$ & $4.75 \times 10^{5}$ & 1.05 & 533 & 1.36 & 0.55 & 0.28 & 10 & 51 \\
\hline
\end{tabular}

Like in previous work (Delrieu et al., 1997; Serrar et al., 2000), we choose here to optimize the radar calibration factor $\delta_{C}$, assuming the DSD and the subsequent $Z-k$ relationship to be known. Since no DSD data were available for the Slovenian case, we actually considered a series of $Z-k$ relationships calculated from various DSD models described in the literature and summarized in Delrieu et al., 2000. This includes DSD models valid for widespread and thunderstorm rainfall and a Cévennes DSD model established in a French region prone to intense and long-lasting rain events resulting mostly from shallow convection triggered by the orography. The corresponding $Z-k$ and $Z-R$ relationships coefficients calculated for the $\mathrm{C}$-band frequency using the Mie scattering model are listed in Table 2.

For the optimization, we used the radar data from the lowest elevation $\left(0.5^{\circ}\right)$. The reflectivity profile was extracted from the ground-clutter processed data and the reference values from the raw reflectivity data. Considering synchronous measurements for the PIA and the reflectivity profiles proved to be important in the present case study due to the fast dynamics of the convective cells. We choose the Nash efficiency between the calculated and measured PIAs as the optimization criterion. It can be noticed however that the PIA can be calculated from Eq. (5) only if $S_{m}\left(r_{0}, r_{M}\right) / \delta_{c}^{1 / \beta}<$ 1 (since $A\left(r_{0}\right)=1$ here). Such a condition may not be fulfilled for a growing number of profiles as $\delta_{C}$ decreases. These situations correspond to the well-known divergences of the forward attenuation correction scheme (e.g., Marzoug and Amayenc, 1994), also known as the Hitschfeld-Bordan algorithm. It may happen however that divergences occur for a number of comparison points while the considered $\delta_{C}$ value is optimal for the majority of points. To cope with this problem, we have limited the calculated PIA to the maximum measured value $(20 \mathrm{~dB})$ and we have accounted for such capped calculated PIA values in the optimization criterion evaluation. Illustrations of the optimization procedure for the Cévennes $Z-k$ relationship are presented in Fig. 3. The optimization results are listed in Table 2 for the various $Z-k$ relationships. Interestingly, the optimal $\delta_{C}$ values are very similar for the three $Z-k$ relationships: the factors are between 0.55 and 0.59 corresponding to a radar underestimation of 2.6 and $2.5 \mathrm{dBZ}$, respectively. Note that such factors compensate for a radar calibration error and also for the bias due to an eventual mismatch of the considered $Z-k$ relationship. The similarity of the correction factors from one $Z-k$ relationship to the next does not necessarily mean that such a bias is negligible but rather that the $Z-k$ relationships tested lead to similar PIA values for the range of rainrates observed.

Once the parameters of the attenuation equation have been estimated, Eqs. (1) and (4) form the basis for the HitschfeldBordan algorithm. As already mentioned, such an algorithm may diverge; Delrieu et al. (1999a) proposed to limit the maximum PIA to be corrected to a pre-fixed value comprised between 10 and $20 \mathrm{~dB}$, regardless of the considered wavelength. We will test in Sect. 5 the influence of such an additional parameter in terms of rainfall estimation.

\section{Radar quantitative precipitation estimation}

We examine hereafter other error sources in radar QPE and the way they interact with the attenuation problem. In the first subsection, a general discussion is proposed together with a brief description of the TRADHy software used in this work. Subsection 4.2 and 4.3 are dedicated to the analysis of screening and vertical profile of reflectivity effects, respectively, for the Slovenian case.

\subsection{Physically-based data processing for radar QPE}

Expanding the weather radar equation (see for instance Doviak and Zrnic, 1993, chapter 4), one may write a more detailed expression for the measured reflectivity factor 
compared to Eq. (1) as:

$Z_{m}(r)=\delta_{C} r^{2} \iiint_{V} \frac{A(s, \theta, \phi) S(s, \theta, \phi) W(s, \theta, \phi) \eta(s, \theta, \phi)}{s^{4}} d V$

where $(s, \theta, \phi)$ are spherical coordinates of a given elementary volume of atmosphere relative to the radar location and $V\left[\mathrm{~L}^{3}\right]$ is the radar resolution volume. The reflectivity $\eta$ (sum of the backscattering cross sections of the hydrometeors per unit volume, $\left.\left[\mathrm{L}^{2} \mathrm{~L}^{-3}\right]\right)$ is proportional to the reflectivity factor $Z\left[\mathrm{~L}^{6} \mathrm{~L}^{-3}\right]$. The function $W[-]$ represents the product of the radial and angular weighting functions associated with the transmitter-receiver and the antenna characteristics, respectively. Let $S$ and $A[-]$ be the screening and the rain attenuation factors, respectively. Equation (8) is useful to illustrate that: (1) a radar measurement is an integral over a volume (which size and height above the ground evolve as a function of range); (2) more standard expressions for the weather radar equation assume the reflectivity to be homogeneous over the radar resolution volume, while a wellknown source of reflectivity heterogeneity is associated with the vertical variation of the temperature and DSD profiles; (3) screening and rain attenuation may introduce additional sources of heterogeneity along the radial direction. Screening effects generally affect only part of the radar resolution volume. Non-uniform beam filling was also shown to significantly alter attenuation correction schemes (e.g., Gosset and Zawadzki, 2001). Equation (8) expresses the complexity of the radar QPE which is likely to be affected by instrumental and sampling errors. These errors are associated with the high variability of rainfall and with environmental factors resulting in significant heterogeneity within the radar resolution volume.

Delrieu et al. (2009) have described a developmental radar QPE processing system called TRADHy. The TRADHy strategy, focused on radar QPE from non-coherent volume scanning data, consists of four steps. A pre-processing step is aimed at checking radar calibration stability, determining the detection domain and characterizing dry-weather clutter. During the course of a rain event, identifications are carried out to dynamically determine clutter, rain types and the corresponding vertical profiles of reflectivity (VPR). Next, corrections for both clutter and screening effects, along with a projection of measured reflectivities onto the ground level using rain-typed VPRs are performed. As a final step, rainfall is estimated at ground level by considering reflectivity-rain rate conversion that may depend on rain type. A strong constraint imposed is to use only radar data for such a processing sequence. Rain gauge measurements are reserved for assessing the radar QPE and build error models. TRADHy was developed so far for non-attenuated radar frequencies (e.g., S-band). Preliminary consideration of the rain attenuation at $\mathrm{C}$-band is proposed in the present article for the Slovenian case.
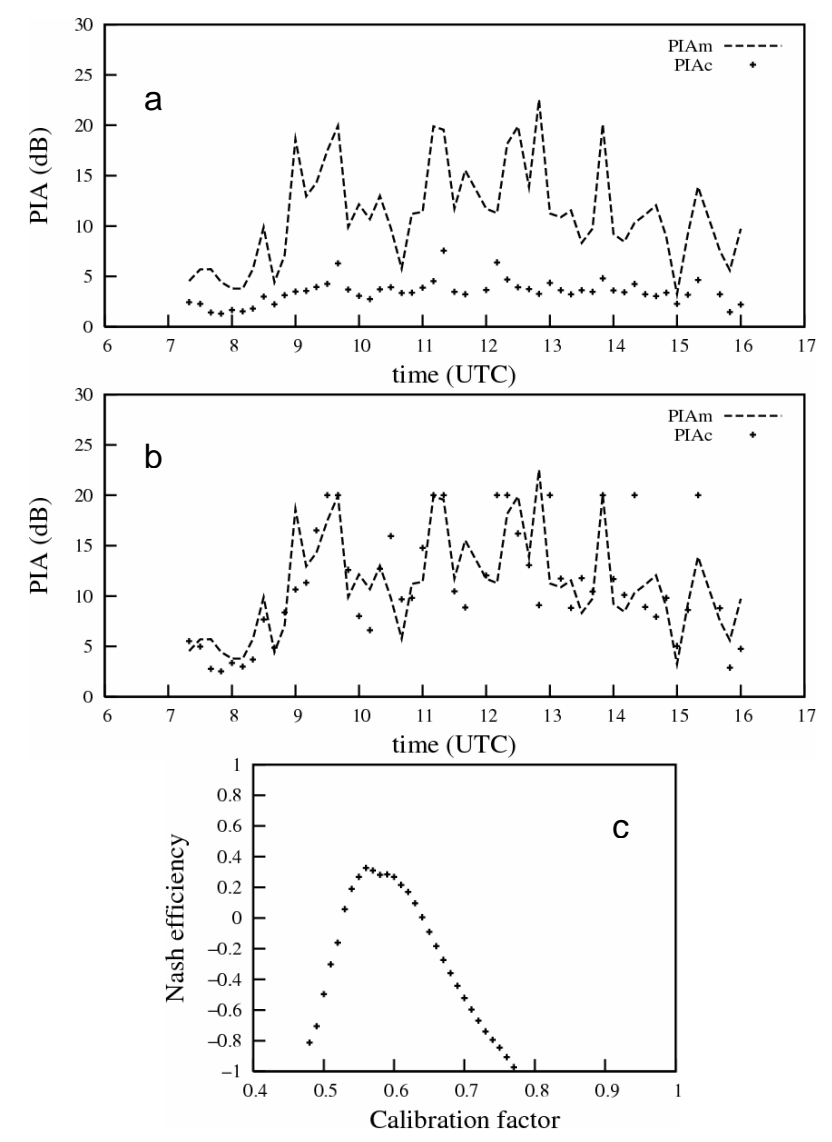

Fig. 3. Illustration of the $\delta_{C}$ optimization procedure. Time series of the measured and calculated PIAs (a) with $\delta_{C}=1$ (raw data), (b) with $\delta_{C}=0.56$ (optimal value). (c) Evolution of the Nash criterion evaluated between the calculated and measured PIAs as a function of $\delta_{C}$. Note that PIAs corresponding to divergences of the attenuation equation are artificially set to $20 \mathrm{~dB}$ and accounted for in the optimization. The Cévennes relationships are considered for the DSD parameterization.

\subsection{Ground clutter and screening effects}

Figure 1 shows ground clutter derived from dry-weather radar images. Figure 2 illustrates the stability of ground clutter prior to and after the rain event, an indication of the probable stability of the transmitter-receiver unit during the rain event. To complement the characterization of the radar detection domain, simulations of the screening effects were realized with a digital terrain according to the procedure described by Delrieu et al. (1995). Figure 4 shows the results obtained for the lowest elevation angles $\left(0.5^{\circ}\right.$ and $\left.1^{\circ}\right)$. The mountains induce very significant screening effects. Higher elevation angles are basically free of screening effects. Note that a narrow but severe mask affects the Železniki watershed with total occultation over the southern part of the watershed for the $0.5^{\circ}$ angle while the maximum screening factor is 

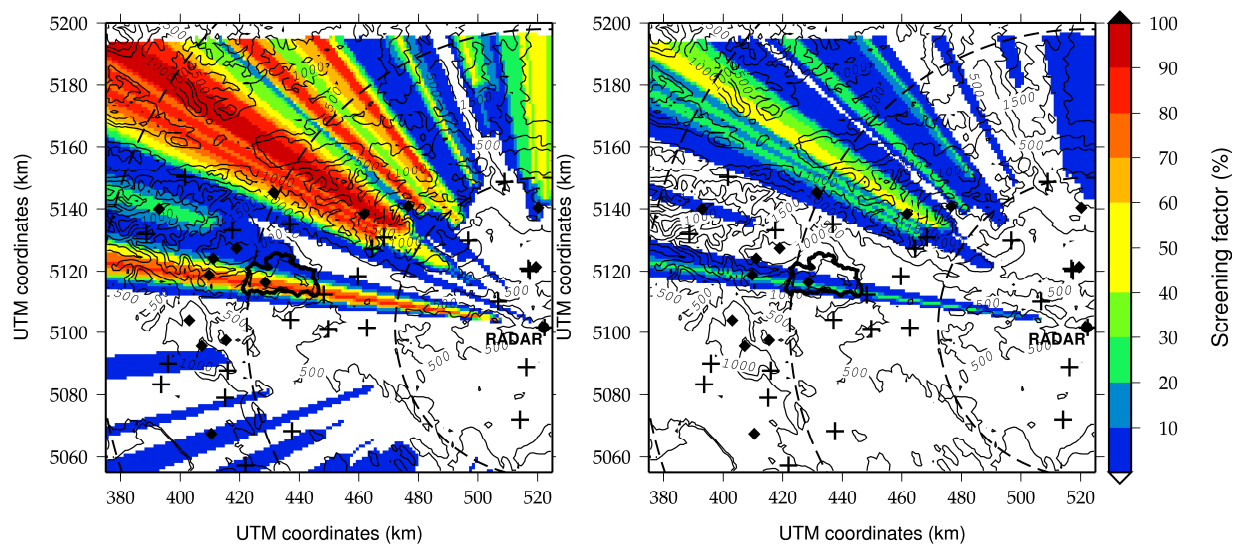

Fig. 4. Screening factors expressed in percent of the transmitted power for the lowest elevation angles $\left(0.5^{\circ}\right.$ left; $1^{\circ}$ right $)$. Note that the watershed of interest is severely masked in its southern part.

equal to $30 \%$ for the $1^{\circ}$ angle. Since the information for these two elevation angles is critical for the QPE over the watershed, we have implemented a screening correction based on a simple interpolation scheme of adjacent angular reflectivity values for the two lowest elevation angles. For the larger screening effects in the north-east part of the detection domain, the correction was based on the calculated screening factors (Fig. 4). The screening correction is performed prior to the attenuation correction because of the dependence of the latter on the rainfall occurring between the radar and the range cell of interest.

\subsection{Vertical profiles of reflectivity}

Figure 5 displays the vertical profiles of reflectivity estimated for the 18 September 2007 case. We simply consider here apparent VPRs (Delrieu et al., 2009) calculated by averaging measured reflectivities in a given radar range, $20-90 \mathrm{~km}$ here. Such profiles are normalized by mean reflectivity values observed close to the ground. We considered an altitude range of $0-1500 \mathrm{~m}$ m.s.l. in the present case since the radar altitude is already $950 \mathrm{~mm}$.s.l. With this basic approach, the VPR shape remains influenced (smoothed) by the beam sampling effects, especially in case of sharp vertical gradients related for instance to the presence of a bright band. The normalized apparent VPRs calculated every $10 \mathrm{~min}$ using a one-hour moving time window and the median profile are displayed in Fig. 5. In addition to the VPRs calculated globally over the chosen geographical domain, we realized VPR estimations after separating convective and stratiform regions using variants of the Steiner et al. (1995) and Sanchez-Diezma et al. (2000) algorithms, respectively. The individual VPRs present a rather high variability with slopes between 0 and $-4 \mathrm{~dB} / \mathrm{km}$ above $3 \mathrm{~km}$ m.s.l. The median VPRs are very similar for the global and convective cases with a slope of $-3.6 \mathrm{~dB} / \mathrm{km}$ above $3 \mathrm{~km} \mathrm{~m}$.s.l.
The median of the stratiform VPRs exhibits a smooth peak between 2000 and $4000 \mathrm{~mm}$.s.l. compatible with the radiosoundings available in Udine, Italy, located at about $100 \mathrm{~km}$ east of the region of interest: the $0^{\circ} \mathrm{C}$ isotherm varied there from $3800 \mathrm{~m}$ m.s.l. on 18 September 2007 00:00 UTC to $4000 \mathrm{~mm}$.s.l. on 18 September 2007 12:00 UTC and $2700 \mathrm{~m}$ m.s.l. on 19 September 2007 00:00 UTC. During the most intense part of the rain event (between 07:00 UTC and 14:00 UTC), convection was however the dominant process in the Železniki region, while the stratification of the rain system was observed behind the squall line which occurred during the cold front passage between 19:00 and 21:00 UTC.

To show the influence of rain attenuation, the VPRs estimated prior to and after the attenuation correction are also displayed in Fig. 5. Interestingly, the attenuation correction increases the slope of the VPRs for both the convective and stratiform cases. This could be simply explained by the fact that the rain paths are longer for low elevation angles compared to those of upper elevations. On average, the attenuation correction is therefore stronger for low elevation measurements, resulting in higher normalization values for the VPRs, and the observed increased VPR slopes.

Due to the convection predominance in the region of the affected watershed, the similarity of the convective and global mean VPRs and the non availability of local raintyped $(Z, k, R)$ relationships, we have used the global VPR to represent the vertical variation of the reflectivity in the following section.

\section{Radar QPE assessment}

The radar QPE was implemented for various choices and parameterizations of the processing algorithms. Focus is given hereafter to the sensitivity of the attenuation correction on the $(Z, k, R)$ relationships used, the calibration error and the 
VPRs after attenuation correction
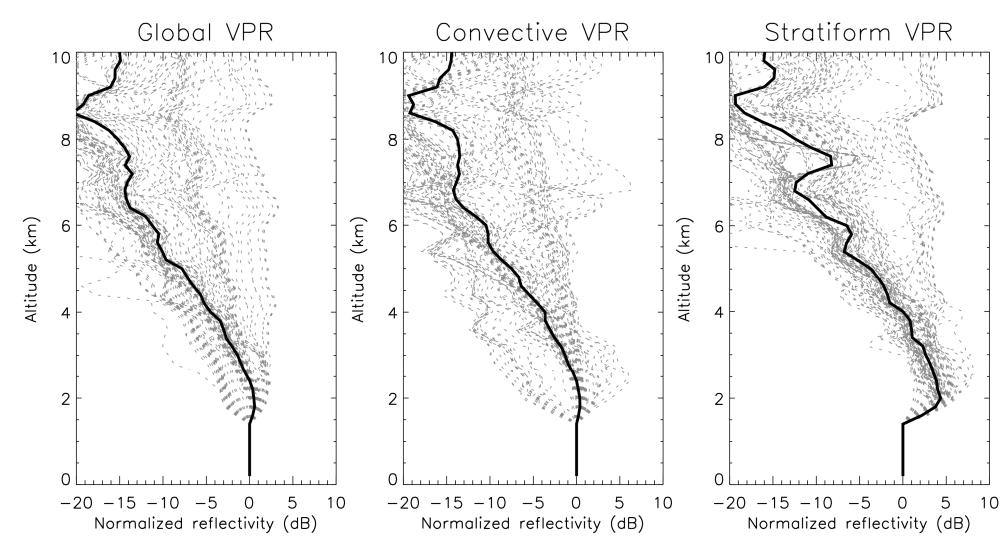

VPRs before attenuation correction
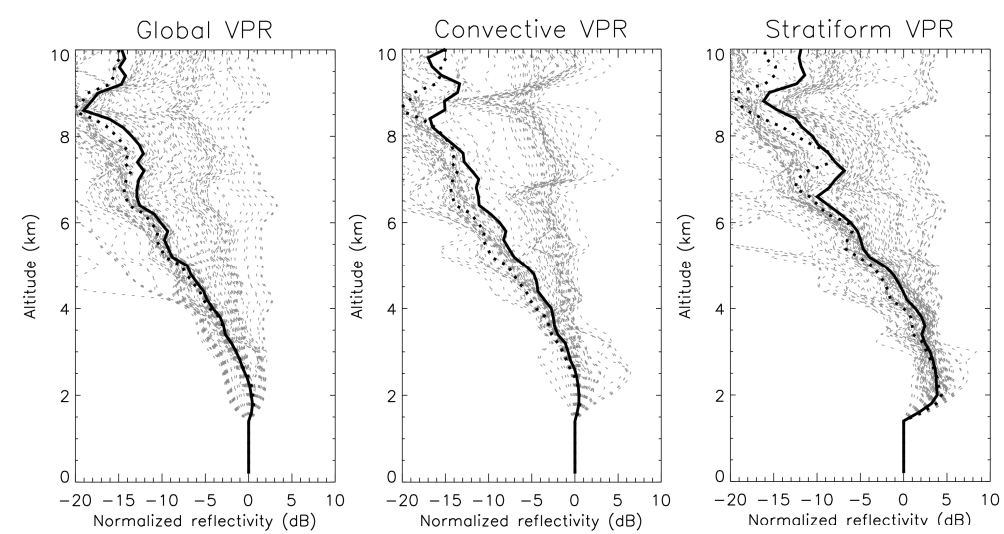

Fig. 5. Normalized vertical profiles of reflectivity after (top) and before (bottom) attenuation correction, estimated globally (left) and for the convective (center) and stratiform (right) regions of the precipitating system. The grey curves correspond to individual VPRs estimated every 10 min over a 60-min time moving window. The continuous line is the median normalized VPR. In the bottom figures, the black dotted lines show the median normalized VPR shown in top graphs to ease the comparison.

maximum PIA value considered in the Hitschfeld-Bordan algorithm. The radar QPE performance was assessed with respect to the rain total amounts observed with the ARSO raingauge network. Note that the raingauge data were critically analyzed with a geostatistical method aimed at detecting the most obvious inconsistencies between neighbouring stations. Considering large integration time steps such as the event time step is certainly efficient to minimizing raingauge random errors. However systematic errors, associated for instance with wind-induced undercatch, may be substantial for this rain event. Classical assessment criteria such as the mean error, the determination coefficient (square of the linear correlation coefficient) and the Nash efficiency were evaluated. The values of the assessment criteria are listed in Table 3; examples of radar-raingauge scatterplots are displayed in Fig. 6.

The raw reflectivity values, simply corrected for screening and VPR effects and then converted into rainrates with a $Z-R$ relationship, severely underestimate the observed rain amounts (first line in Table 3 and Fig. 6a). Application of the $\delta_{C}$ correction alone brings a significant, though insufficient, improvement as can be seen in the second line of Table 3 and Fig. 6b. The combined correction for calibration and attenuation proves to be both effective in improving the radar QPE but also very sensitive on the maximum corrected PIA value used (lines 3-5 in Table 3; Fig. 6c-d). The better estimations are obtained for the $10 \mathrm{~dB}$ maximum PIA for the Cévennes $(Z, k, R)$ relationships. Note in particular that the values greater than $150 \mathrm{~mm}$, corresponding to the most intense rainfall pattern, are almost unbiased and present a small scatter. The higher scatter observed for lower rain amount values is related to poor corrections for both the screening effects (comparison pairs represented by triangles in Fig. 6) in the north-west part of the radar detection domain and for comparison points at ranges greater than $120 \mathrm{~km}$ (comparison points represented by crosses in Fig. 6). Although PIA values up to $20 \mathrm{~dB}$ were observed between the radar and the mountain reference target (Fig. 2), application of this threshold 
Table 3. QPE assessment for various parameterizations of the radar data processing.

\begin{tabular}{|c|c|c|c|c|c|c|c|}
\hline $\begin{array}{l}(Z, k, R) \\
\text { relationships }\end{array}$ & $\delta_{C}$ & $\begin{array}{l}\text { Attenuation } \\
\text { correction }\end{array}$ & $\begin{array}{l}\text { Max } \\
\text { PIA } \\
(d B)\end{array}$ & VPR & $\begin{array}{c}\text { Nash } \\
\text { criterion }\end{array}$ & $\begin{array}{l}\text { Mean } \\
\text { Error } \\
(\mathrm{mm})\end{array}$ & $\begin{array}{l}\text { Determi- } \\
\text { nation } \\
\text { coefficient }\end{array}$ \\
\hline Cévennes & 1.00 & no & - & Median & -0.43 & -68.9 & 0.55 \\
\hline Cévennes & 0.56 & no & - & Median & 0.07 & -50.9 & 0.61 \\
\hline Cévennes & 0.56 & yes & 10 & Median & 0.82 & -11.9 & 0.85 \\
\hline Cévennes & 0.56 & yes & 10 & Time-adaptive & 0.80 & -16.8 & 0.85 \\
\hline Cévennes & 0.56 & yes & 15 & Median & 0.79 & -2.9 & 0.82 \\
\hline Cévennes & 0.56 & yes & 20 & Median & 0.59 & 15.0 & 0.80 \\
\hline Widespread & 0.59 & yes & 10 & Median & 0.82 & 4.4 & 0.85 \\
\hline Widespread & 0.59 & yes & 15 & Median & 0.75 & 10.0 & 0.85 \\
\hline Widespread & 0.59 & yes & 20 & Median & 0.57 & 18.6 & 0.82 \\
\hline Thunderstorm & 0.55 & yes & 10 & Median & 0.68 & -27.6 & 0.81 \\
\hline Thunderstorm & 0.55 & yes & 15 & Median & 0.70 & -16.0 & 0.74 \\
\hline Thunderstorm & 0.55 & yes & 20 & Median & 0.55 & 1.4 & 0.66 \\
\hline
\end{tabular}
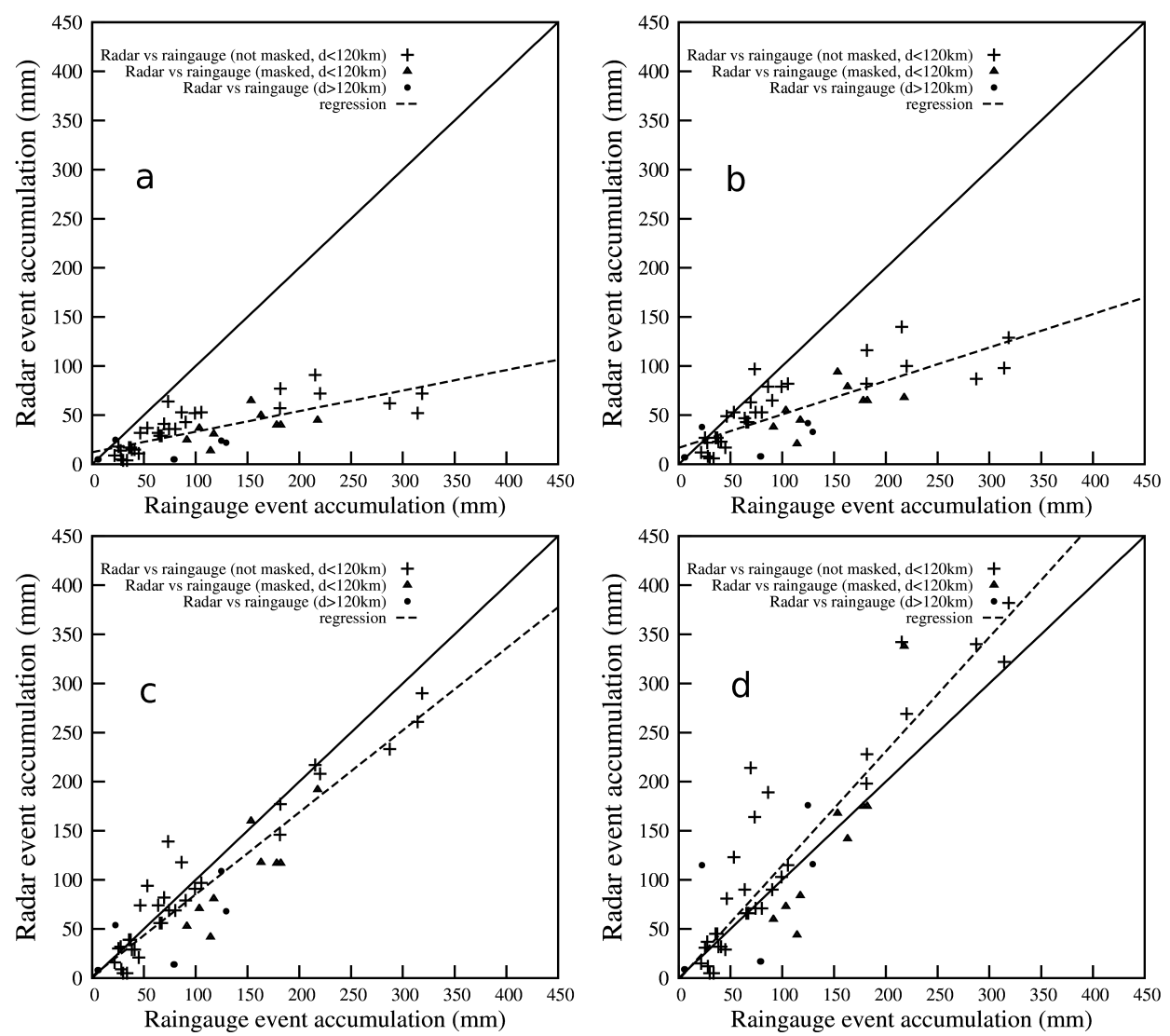

Fig. 6. Scatterplots of radar estimates versus raingauge measurements at the event time scale with the following radar data processing: (a) screening and VPR correction of the raw reflectivity; (b) in addition, the $\delta_{C}$ correction is performed; (c) in addition, the attenuation correction is performed with a maximum corrected PIA of $10 \mathrm{~dB}$; (d) same as (c) with a maximum corrected PIA of $20 \mathrm{~dB}$. The Cévennes $(Z, k, R)$ relationships are used. 
yields to unacceptable QPE overestimations (Fig. 6d). The assessment criteria are very significantly downgraded compared to both the $10 \mathrm{~dB}$ and $15 \mathrm{~dB}$ thresholds (Table 3). As suggested by Delrieu et al. (1999a), the former threshold appears as a good compromise here with the implementation conditions considered (adjustment for the radar calibration error, unique set of $(Z, k, R)$ relationships). Finally, Fig. 7 allows for a comparison of the raingauge observations spatialized with the Kriging technique with the radar estimates obtained with the MRT technique (PIA threshold of $10 \mathrm{~dB}$ ).

Comparison of the results obtained with the three sets of $(Z, k, R)$ relationships indicates that the widespread and Cévennes relationships lead to good and almost equivalent results (with a slight superiority for the widespread relationships parameterization, however) while the radar QPE for the thunderstorm relationships lead to worse results. In particular, although the radar calibration factor was adjusted, the radar QPE remains significantly underestimated in that case for the 10 and $15 \mathrm{~dB}$ PIA thresholds while the attenuation equation instability worsen the estimates for the $20 \mathrm{~dB}$ PIA threshold. Such results call for several comments. Firstly, a certain degree of equifinality is likely for the attenuation correction parameterization and the adjustment of the calibration factor allows compensation for part of the possible inadequacy of the $Z-k$ relationship. It should be noted that since the MRT works with PIA estimates and allows for an adjustment of the radar calibration for a given $Z-k$ relationship, the $Z-R$ conversion is not optimized in any manner in this procedure. Using $(Z, k, R)$ models consistent with the underlying DSDs is therefore particularly critical for such an approach. In this respect however, the fact that the widespread relationships yield the best results for this convective event illustrate the gap between physical parameterizations that can be determined over small volumes with disdrometers and the effective parameterizations at the scale of the radar resolution volume.

As a final test, lines 3 and 4 in Table 3 allow comparison of the results obtained by considering a time-adaptive global VPR and the median global VPR. The latter solution yields the better results and it was then preferred in the radar QPE implementation for the other simulations listed in Table 3. Consideration of rain-typed VPRs (not shown here) also proved to slightly downgrade the radar QPE performance. This tends to indicate the lack of consistency of some of the individual VPRs and the need to make adaptive corrections more robust.

\section{Conclusions}

This article is dedicated to radar rainfall estimation for the post-event analysis of a flash flood event that occurred on 18 September 2007 in Slovenia. The utility of the Mountain Reference Technique (MRT) is demonstrated to quantify

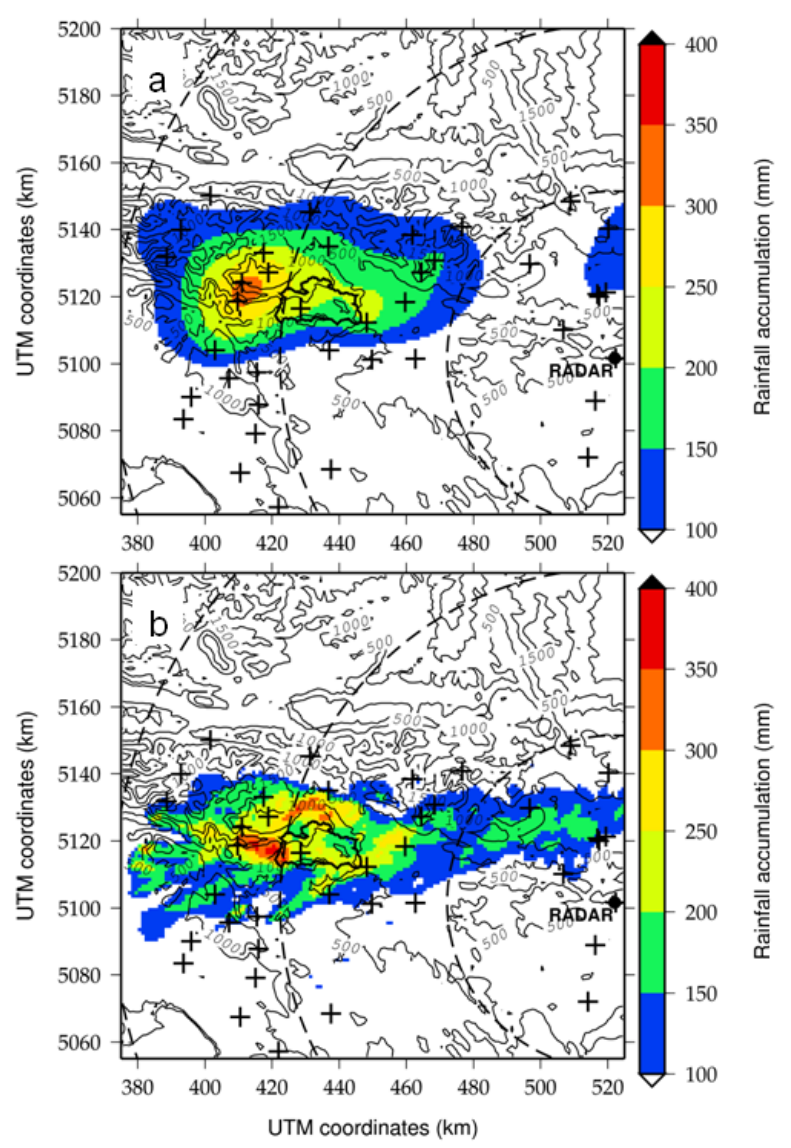

Fig. 7. Raingauge (a) and radar (b) rainfall fields at the event time scale for rainfall values greater than $100 \mathrm{~mm}$. The radar estimates are obtained with the MRT technique by considering the Cévennes DSD parameterization and a PIA threshold of $10 \mathrm{~dB}$.

and correct rain attenuation effects that affect C-band radar measurements in heavy rain. Maximum PIAs between 15 and $20 \mathrm{~dB}$ are measured using mountain returns for pathaveraged rain rates between 10 and $15 \mathrm{~mm} \mathrm{~h}^{-1}$ over a 120 $\mathrm{km}$ path. By considering the PIA constraint equation, the MRT allows estimation of an effective radar calibration correction factor, assuming a DSD model and the subsequent $(Z, k, R)$ relationships to be known. Besides rain attenuation, screening effects are quantified using a geometrical calculation based on a digitized terrain model of the region. A narrow mask affecting the two lowest elevation angles above the Železniki watershed complicates the estimation problem for this region of special interest. The vertical structure of the reflectivity is modelled with the normalized apparent VPR estimated globally without rain type separation. Implementation of the radar data processing indicates that: (1) the combined correction for radar calibration and attenuation over the entire detection domain using the Hitschfeld-Bordan algorithm allows obtaining good radar QPEs (Nash criterion of 0.8 at the event time scale), especially for the most intense 
rainfall period; (2) due to the attenuation equation instability, it is however compulsory to limit the maximum PIA to be corrected to about $10 \mathrm{~dB}$; (3) the results also proves to be sensitive on the choice of the $(Z, k, R)$ relationships. The convective nature of the precipitation explains the rather good performance obtained. For more contrasted rainy systems with convective and stratiform regions, the combination of the vertical (VPR) and radial (attenuation, screening) sources of heterogeneity yields a still very challenging radar QPE problem.

The large sensitivity of the forward attenuation correction scheme on the maximum PIA, even with an adjusted radar calibration, prevents implementation of such an algorithm in real-time application. However, in the context of post-event studies, this simple method controlled with some raingauge measurements at the event time step proves to be useful. It is worth reminding that backward correction algorithms, starting from a reference target, are very stable and much less sensitive to parameterization errors compared to the forward scheme used herein (Marzoug and Amayenc, 1994). Such algorithms could be implemented easily if the region of interest was surrounded by a belt of mountain targets.

The radar QPE space-time series are now being used as input for the distributed hydrologic modelling of the Železniki flash flood. A striking result of the radar QPE analysis (Fig. 7b) indicates that maximum rainfall occurred outside the Železniki watershed. This is motivating additional field investigation to assess the flash-flood impacts in this less vulnerable area.

Acknowledgements. The authors are grateful to A. Zgonc from ARSO for providing the raw radar data used in this work. This study was funded by the HYDRATE project of the European Community (GOCE 037024) and the Cluster Environnement of the Rhône-Alpes Region.

Edited by: M. Mikos

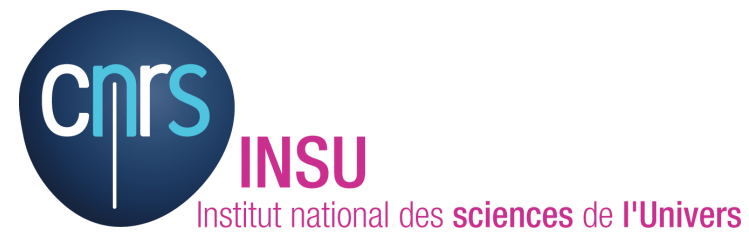

The publication of this article is financed by CNRS-INSU.

\section{References}

Andrieu, H., Creutin, J. D., Delrieu, G., and Faure, D.: Use of a weather radar for the hydrology of a mountainous area, Part I: Radar measurement interpretation, J. Hydrol., 193, 1-25, 1997.

Collier, C. G.: Applications of weather radar systems, Ellis Horwood, 294 pp, 1989.
Delrieu, G., Creutin, J. D., and Andrieu, H.: Simulation of X-band weather radar mountain returns using a digitized terrain model, J. Atmos. Ocean. Tech., 12, 1038-1049, 1995.

Delrieu, G., Caoudal, S., and Creutin, J. D.: Feasibility of using mountain return for the correction of ground based X-band weather radar data, J. Atmos. Ocean. Tech., 14, 368-385, 1997.

Delrieu, G., Hucke, L., and Creutin, J. D.: Attenuation in rain for $\mathrm{X}$ - and C- band weather radar systems operating in heavy rainfall: sensitivity with respect to the drop size distribution, J. Appl. Meteorol., 38, 57-68, 1999a.

Delrieu, G., Serrar, S., Guardo, E., and Creutin, J. D.: Rain measurement in hilly terrain with X-band radar systems: Accuracy of path-integrated attenuation estimates derived from mountain returns, J. Atmos. Ocean. Tech., 16, 405-416, 1999 b.

Delrieu, G., Andrieu, H., and Creutin, J. D.: Quantification of pathintegrated attenuation for X- and C-band weather radar systems operating in heavy rainfall, J. Appl. Meteorol., 39, 840-850, 2000.

Delrieu, G., V. Ducrocq, E. Gaume, J. Nicol, O. Payrastre, E. Yates, P.-E. Kirstetter, H. Andrieu, P. A. Ayral, C. Bouvier, J. D. Creutin, M. Livet, A. Anquetin, M. Lang, L. Neppel, C. Obled, J. Parent-du-Chatelet, G. M. Saulnier, Walpersdorf, A., and Wobrock, W.: The catastrophic flash-flood event of 8-9 September 2002 in the Gard region, France: a first case study for the Cévennes-Vivarais Mediterranean Hydro-meteorological Observatory, J. Hydrometeorol., 6, 34-52, 2005.

Delrieu, G., Boudevillain, B., Nicol, J., Chapon, B., Kirstetter, P.E., Andrieu, H., and Faure, D.: Bollène 2002 experiment: radar rainfall estimation in the Cévennes-Vivarais region, France, J. Appl. Meteorol. Clim., in press, 2009.

Doviak, R. J., and Zrnic, D. S.: Doppler radar and weather observations, 2nd edn. Academic Press Inc., 562 pp, 1993.

Gaume, E.: Post flash-flood investigation - methodological note, Floodsite European Research Project, available at: http://www. floodsite.net/, report D23.2., 62 pp, 2006.

Geotis, S. G.: Some measurements of the attenuation of 5-cm radiation in rain, Preprints 16th Conf. on Radar Meteorology, Houston, TX, Amer. Meteor. Soc. 63-66, 1975.

Germann, U., Galli, G., Boscacci, M., and Bolliger, M.: Radar precipitation measurement in a mountainous region, Q. J. Roy. Meteor. Soc., 132, 1669-1692, 2006.

Gosset, M. and Zawadzki, I.: Effect of Nonuniform Beam Filling on the Propagation of the Radar Signal at X-Band Frequencies. Part I: Changes in the $\mathrm{k}(\mathrm{Z})$ Relationship, J. Atmos. Ocean. Tech., 18(7), 1113-1126, 2001.

Joss, J. and Waldvogel, A.: Precipitation measurement and hydrology, Radar in Meteorology: Battan Memorial and 40th Anniversary Radar Meteorology Conference, edited by: Atlas, D., Amer. Meteor. Soc., 577-606, 1990.

Leijnse, H., Uijlenhoet, R., and Stricker, J.N.M.: Rainfall measurements using radio links from cellular communications networks, Water Resour. Res., 43, W03201, doi:10.1029/2006WR005631, 2007.

Marzoug, M., and Amayenc, P.: A class of single and dualfrequency algorithms for rain-rate profiling from a spaceborne radar: Part 1- Principle and tests from numerical simulations, J. Atmos. Ocean. Tech., 11, 1480-1506, 1994.

Meneghini, R., Eckerman, J., and Atlas, D.: Determination of rain rate from a spaceborne radar using measurements of total 
attenuation, IEEE T. Geosci. Remote., GE-21, 34-43, 1983.

Ogden, F. L., Sharif, H. O., Senarath, U. S., Smith, J. A., Baeck, M. L., and Richardson, J. R.: Hydrologic analysis of the Fort Collins, Colorado flash flood of 1997, J. Hydrol., 228, 82-100, 2000.

Pellarin, T., Delrieu, G., Saulnier, G. M., Andrieu, H., Vignal, B., and Creutin, J. D.: Hydrologic visibility of weather radar systems operating in mountainous regions: Case study for the Ardèche catchment, France, J. Hydrometeorol., 3, 539-555, 2002.

Smith, J. A., Baeck, M. L., Steiner, M., and Miller, A. J.: Catastrophic rainfall from an upslope thunderstorm in the central Appalachians: the Rapidan storm of 27 June 1995, Water Resour. Res., 32, 3099-3113, 1996.
Sanchez-Diezma, R., Zawadzki, I., and Sempere-Torres, D.: Identification of the bright band through the analysis of volumetric radar data, J. Geophys. Res., 105(D2), 2225-2236, 2000.

Serrar, S., Delrieu, G., Creutin, J. D., and Uijlenhoet, R.: Mountain reference technique - The use of mountain returns to calibrate weather radars operating at attenuating wavelengths, J. Geophys. Res., 105, 2281-2290, 2000.

Steiner, M., Houze, R. A., and Yuter, S. E.: Characterization of three dimensional storm structure from operational radar and rain gauge data, J. Appl. Meteorol., 34, 1978-2007, 1995. 